06

\title{
Формирование нанофазного смачивающего слоя и рост металла на полупроводнике
}

(c) Н.И. Плюснин

Институт автоматики и процессов управления ДВО РАН, Владивосток, Россия

E-mail: plusnin@iacp.dvo.ru

Поступило в Редакцию 26 июня 2018 г.

На основе данных исследования атомной плотности пленки и степени ее однородности в процессе формирования границы раздела $3 d$-переходных металлов $(\mathrm{Cr}, \mathrm{Co}, \mathrm{Fe}, \mathrm{Cu})$ на кремнии обосновывается новая концепция формирования контакта химически активного металла с полупроводником. Согласно этой концепции, при низкотемпературном парофазном осаждении металла на полупроводник происходит формирование двумерного нанофазного смачивающего слоя металла или его смеси с кремнием толщиной в несколько монослоев, который оказывает существенное влияние на процесс формирования и структуру границы раздела. Эта концепция изменяет взгляд на формирование контакта металла с полупроводниковой подложкой: необходимо учитывать не только процессы образования поверхностных фаз, кластеров и/или процесс перемешивания, но и эффект упругого смачивания подложки образующимися фазами.

DOI: 10.21883/PJTF.2018.21.46857.17439

Омические и барьерные контакты между немагнитным и/или ферромагнитным металлом и полупроводником и ультратонкие слои металла на полупроводнике имеют большое значение в наноэлектронике $[1,2]$, в частности в наноспинтронике и наноплазмонике. А в последние годы значение металлических контактов и ультратонких слоев еще более возросло в связи с тем, что толщина приборных полупроводниковых слоев уменьшилась на порядки и они приобрели низкоразмерный характер (см., например, [3]).

Вместе с тем до сих пор существует концепция формирования границы раздела металл/полупроводник, которая зародилась еще до 90-х 
годов прошлого века. Согласно указанной концепции, этот процесс связан со взаимной диффузией и реакцией, а также с ростом объемных фаз (см., например, [4]), в частности объемных фаз металл-кремний [2]. При этом рассматриваются четыре типа объемных фаз: поликристаллическая, аморфная, монокристаллическая и эпитаксиальная или псевдоморфная, а рост объемных фаз представлен тремя механизмами: островковый, островковый вслед за послойным-псевдоморфным и послойный.

Сформировалась также концепция, согласно которой образование контакта металл-полупроводник при покрытиях до одного монослоя включает химическую адсорбцию [4,5]. При этом в случае подложки из ковалентных полупроводников (например, кремния) поверхность полупроводника структурно реконструируется с возникновением дальнего порядка [5] и образует вместе с встроенными в нее химически адсорбированными атомами так называемые поверхностные фазы [6]. А после стадии химической адсорбции формируются либо кластеры адсорбата, либо слой его смеси с материалом подложки (слой перемешанной фазы) $[5,7]$.

Дальнейшие исследования показали, что при отжиге перемешанной фазы металла на полупроводнике происходит переход в метастабильную фазу с упорядочением и уплотнением (например, на кремнии [8]), а при последующем увеличении температуры отжига - переход к пленке объемного соединения (силицида) в альтернативной эпитаксиальной ориентации или с той или иной текстурой в зависимости от состава перемешанной фазы [9]. Кроме того, исследования [8] показали также, что 1) толщина перехода этой фазы к объемной фазе находится в пределах нескольких монослоев; 2) с уменьшением температуры пара в этой и предшествующей ей фазах происходит уменьшение концентрации кремния вплоть до образования неравновесной фазы металла; 3) образованная из перемешанной фазы упорядоченная метастабильная фаза имеет слоистый характер по глубине и толщину, достигающую нескольких (иногда до шести) монослоев.

Тем не менее обычными методами электронной микроскопии и атомно-силовой микроскопии структуру неравновесной двумерной перемешанной фазы полностью охарактеризовать не удавалось. Так, например, по данным атомно-силовой микроскопии она имела аморфнуюнанозернистую (очевидно, нанофазную) структуру [10].

5 Письма в ЖТФ, 2018, том 44, вып. 21 
Однако обычно, если имеется небольшая (до 4-5\%) разница в параметрах решеток подложки и пленки, при неравновесных условиях образуется псевдоморфный смачивающий слой с толщиной в несколько монослоев, который адаптируется по структуре к подложке, вызывая в ней напряжения, и из которого затем, в процессе роста (по механизму Странски-Крастанова), формируются островки объемной фазы (см., например, $[11,12])$. А в случае систем адсорбат-подложка с большим рассогласованием решеток традиционная теория предполагает рост когерентных и мультислойных агрегатов с углом смачивания, близким к $90^{\circ}$, и при их слиянии - формирование сплошной мелкозернистой (очевидно, нанофазной) пленки адсорбата [13].

Очевидно, что эволюция структуры и свойств растущей пленки металла и границы раздела металл/полупроводник может быть при определенных условиях связана не только с упомянутыми выше стадиями роста и перемешиванием, но и с формированием двумерного смачивающего слоя, который адаптируется к подложке за счет своей напряженной и нанофазной структуры и за счет структурной перестройки граничной области полупроводника.

Для обнаружения этого эффекта смачивания (упругой адаптации слоя металла к подложке полупроводника) была разработана соответствующая методика исследования $[8,10]$. Суть данной методики состоит в том, что по положению и форме пика плазмонных потерь в спектре характеристических потерь энергии электронов можно проследить за электронной плотностью в пленке и ее однородностью и даже за атомной плотностью и ее однородностью, если состав пленки не изменяется. Поэтому указанная методика предполагает одновременное исследование (в пределах соответствующей глубины зондирования) двумя методами: спектроскопии потерь энергии электронов и электронной оже-спектроскопии. Отметим, что глубина зондирования должна соответствовать диапазону толщин слоев, при которых происходит переход к первой объемной фазе $(1-10 \mathrm{ML})$. Для этого в обоих методах значение энергии первичных электронов должно быть равным $\sim 300 \mathrm{eV}$, чему приблизительно соответствует глубина зондирования в $3 \mathrm{ML}$.

Вместе с тем существует единственная возможность получить пленку металла на кремнии с неизменным составом - вырастить чистый металл на кремнии. Для реализации этой возможности был разработан и использован способ осаждения металла при пониженной температуре пара [8], когда металл осаждают из ультратонкой полоски,

Письма в ЖТФ, 2018, том 44, вып. 21 
предварительно осаждаемой на тонкую $(10-20 \mu \mathrm{m})$ Та-ленту. При этом площадь полоски и Та-ленты должна быть больше площади подложки $\mathrm{Si}$, а расстояние между ними и подложкой - меньше размера подложки. Это обеспечивает однородность пленки, пониженную температуру пара и одновременно оптимальную скорость осаждения. В результате появляется возможность уменьшить температуру пленки во время роста.

Исследования образцов, полученных при осаждении из пара с пониженной температурой (или кинетической энергией) и одновременно при комнатной температуре подложки, показали, что в этом случае по данным электронной оже-спектроскопии металл и кремний в пленке на стадии формирования неравновесной фазы не перемешиваются $[8,10]$. При этом до формирования объемной фазы, при толщине металла в несколько монослоев $(\leqslant 6 \mathrm{ML})$, величина энергии и ширина пика объемных плазмонных потерь в спектре потерь энергии пленки были соответственно меньше и больше, чем у объемной фазы металла [10]. Первый факт свидетельствует о том, что до образования объемной фазы формировался некий смачивающий слой металла, который имеет уменьшенную и адаптированную к подложке плотность, а второй факт указывает на то, что эта плотность имеет неоднородную (нанофазную) структуру.

В отличие от этого при повышенной температуре пара происходило перемешивание и состав смачивающего слоя был промежуточным между кремнием и металлом, а его переход к объемной фазе происходил при большей толщине $[8,10]$. Очевидно, что при комнатной температуре подложки образование нанофазного смачивающего слоя металла или его смеси с кремнием происходило не только при пониженной температуре пара, но и при повышенной.

Действительно, когда металл и кремний не перемешиваются, уменьшенная и неоднородная атомная плотность нанофазного смачивающего слоя связана с ее собственной структурой, а не с составом. Анализ экспериментальных данных $[8,10]$ показывает, что этот слой адаптирован к подложке по плотности и состоит из зерен (нанокластеров) с неоднородной, в целом пониженной по отношению к объемной фазе металла плотностью (рис. 1 и вставка справа). С теоретической точки зрения эту адаптацию пленки к подложке можно объяснить тем, что нанокластеры „натянуты на подложку до совпадения плотности в смыкающихся на границе раздела слоях атомов металла и кремния. При этом неоднородной деформации подвергнуты как сами кластеры,

$5^{*}$ Письма в ЖТФ, 2018, том 44, вып. 21 


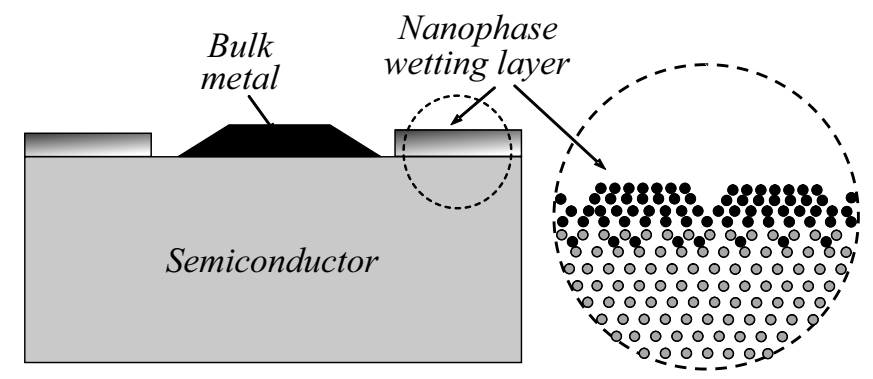

Рис. 1. Схема формирования островков объемного металла из сплошного двумерного нанофазного смачивающего слоя во время формирования границы раздела металл-полупроводник и схематическое изображение структуры этого смачивающего слоя в увеличенном виде (справа).

так и поверхностные слои подложки (эта деформация на вставке не показана). Если принимать во внимание теорию твердых шаров, то указанная выше адаптация кроме упругого сжатия и растяжения может быть реализована за счет вакансий и атомов внедрения, а также за счет разбиения пленки и граничного слоя подложки на зерна (кластеры) и домены, разделенные дислокациями, соответственно. Кроме того, они могут быть реализованы за счет других дефектов (дефектов упаковки и т.п.), а также частичного (в пределах неравновесной растворимости) перемешивания атомов металла и полупроводника.

Исследовать изменения плотности можно более детально, но для этого необходимо вычитать спектр потерь подложки из исходного спектра потерь системы пленка-подложка. Такой дифференциальный спектр был получен, например, для пленки Co на Si вычитанием вклада подложки с весом, оптимальным с точки зрения соответствия формы пика объемных плазмонных потерь идеальной лоренцевой форме $[8,10]$. Действительно, как показывает анализ дифференциальных спектров на рис. 2, $a$, в пленке последовательно образуются слой поверхностной фазы Co $(B)$, затем, более плотный смачивающий монослой Со (фаза $C)$, далее более плотный и двумерный - нанофазный по структуре смачивающий мультислой Со (фаза $D$ ), а после него - более плотный слой объемного Сo $(E)$.

Письма в ЖТФ, 2018, том 44, вып. 21 


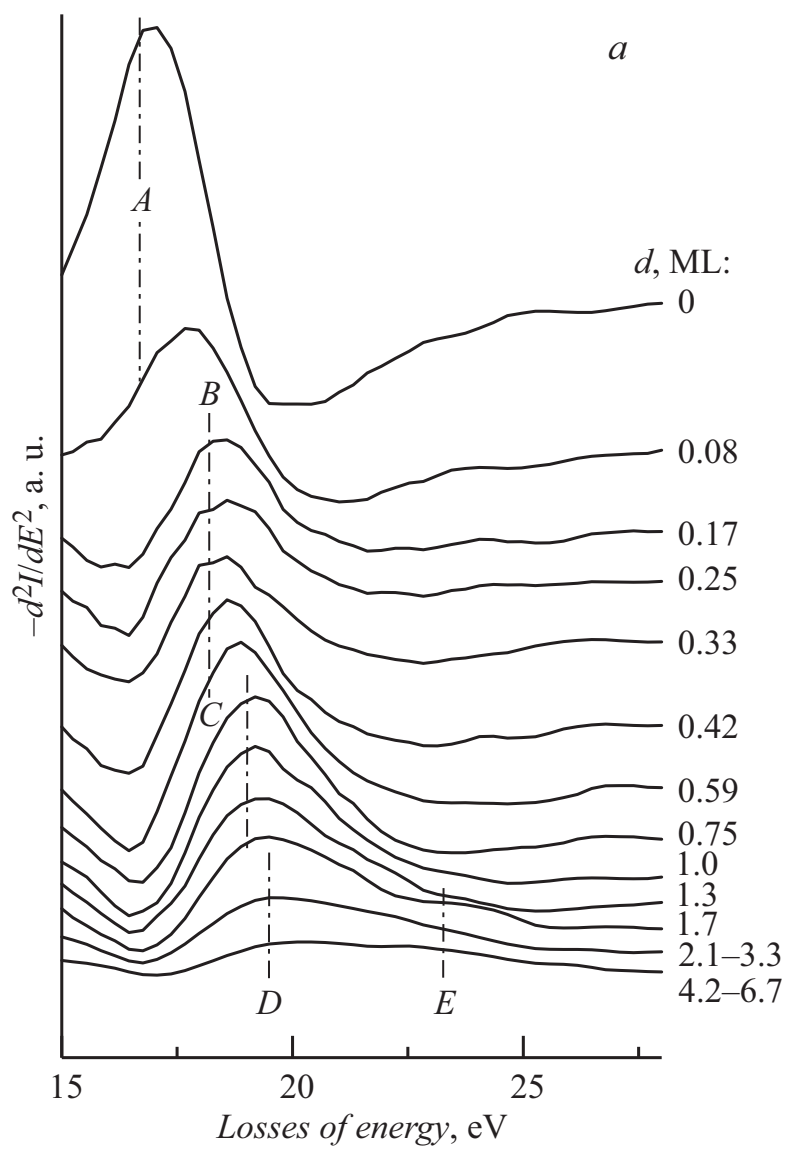

Рис. 2. Дифференциальные спектры потерь энергии Со на $\mathrm{Si}$ (111) на стадиях формирования смачивающего слоя и перехода к объемной фазе [8] (a) и зависимость энергии плазмонного сателлита оже-пика $\mathrm{Si}(92 \mathrm{eV})$ на стадии образования смачивающего слоя [10] $(b)$.

Дополнительное подтверждение смачивания подложки кремния слоем металла дают более быстрое уменьшение интенсивности пика объемных плазмонных потерь, чем его теоретическое экспоненциальное

Письма в ЖТФ, 2018, том 44, вып. 21 


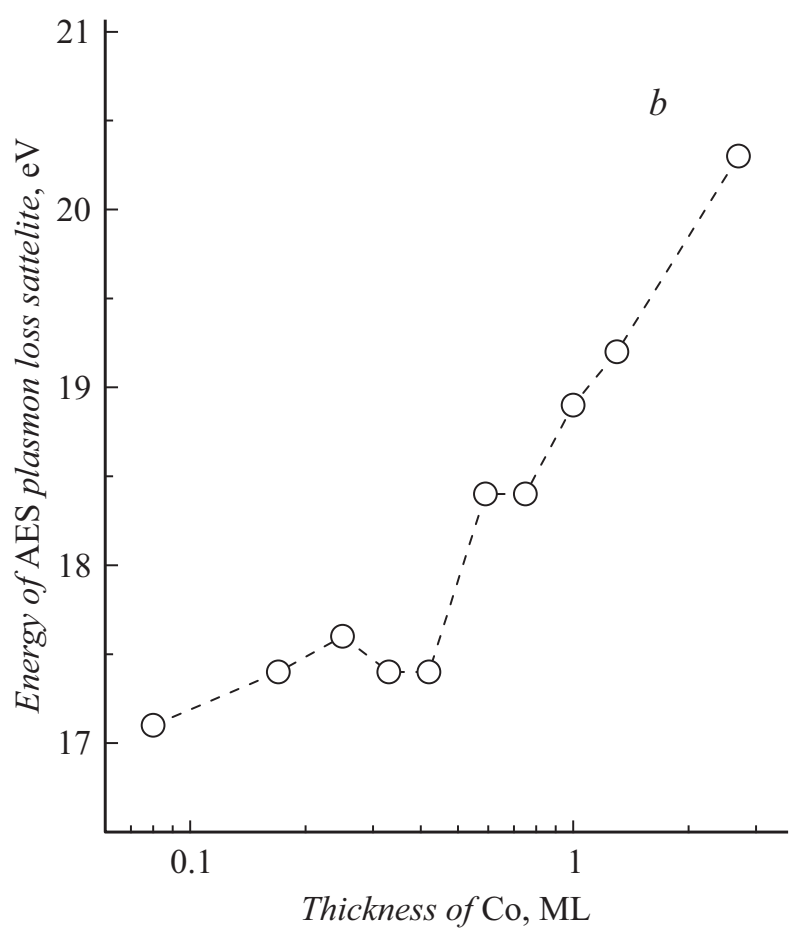

Рис. 2 (продолжение).

затухание от подложки, при идеальной-послойной-модели роста [8], и быстрое, (почти на $5 \mathrm{eV}$ в первых трех монослоях) изменение положения плазмонного сателлита оже-пика кремния в пленках $\mathrm{Cr}, \mathrm{Fe}$ и $\mathrm{Co}$ [10] (рис. $2, b)$. Этот сателлит преимущественно отражает плотность самого кремния вблизи атомов кремния около границы раздела, а его сдвиг по энергии показывает изменение плотности кремния при росте Со, т.е. на этой стадии под действием напряжений в пленке Со происходит сжатие решетки кремния и предположительно ее реконструкция и переход к решетке более плотной фазы кремния.

Подтверждение формирования более плотной фазы кремния дают зависимости оптических спектров $\mathrm{Fe}$ на $\mathrm{Si}(001)$, а также проводимости Co на $\mathrm{Si}(111)$ от толщины [8]. Анализ этих зависимостей показывает

Письма в ЖТФ, 2018, том 44, вып. 21 
аномально высокий рост коэффициента отражения в области энергий фотонов $1.5 \mathrm{eV}$ и глубокий минимум удельного сопротивления при 1-2 ML. Оба факта могут быть также объяснены не чем иным, как формированием металлической и, следовательно, более плотной фазы кремния с более высокими величинами коэффициента отражения и проводимости.

Таким образом, анализ атомной плотности и ее однородности в процессе низкотемпературного парофазного осаждения переходного $3 d$-металла на кремний вместе с другими исследованиями показал формирование двумерного смачивающего слоя с нанофазной структурой, адаптированной к подложке. Это слой влиял на состав и структуру формирующейся объемной фазы, а также на структурное состояние приграничного слоя подложки. Эти результаты дают основания для выдвижения новой концепции формирования контакта металла к полупроводниковой подложке, учитывающей формирование перед объемной фазой нанофазного смачивающего слоя. А новый взгляд на этот процесс открывает новые перспективы применения полученных результатов.

Работа выполнена при частичной финансовой поддержке по программе ДВО РАН (госзадание № 0262-2018-0030).

\section{Список литературы}

[1] Del Alamo J.A. // Nature. 2011. V. 479. P. 317-323.

[2] Chen L.J. // JOM. 2005. V. 57. P. 24-30.

[3] Sung S.J., Yang J.W., Lee P.R., Kim J.G., Ryu M.T., Park H.M., Lee G., Hwang C.C., Kim K.S., Kim J.S., Chung J.W. // Nanoscale. 2014. V. 6. P. 3824 3829.

[4] L"uth H. // Solid surfaces, interfaces and thin films. Berlin: Springer, 2015. 589 p.

[5] Brillson L.J. // Surfaces and interfaces of electronic materials. Weinheim: John Wiley \& Sons, 2010. P. 327-364.

[6] Oura K., Lifshits V.G., Saranin A.A., Zotov A.V., Katayama M. // Surface science: an introduction. Berlin-Heidelberg-N.Y.: Springer Science \& Business Media, 2013. $440 \mathrm{p}$.

[7] Weaver J.H. // Phys. Today. 1986. V. 39. P. 24-30.

[8] Plusnin N.I. // Mod. Electron. Mater. 2017. V. 3. P. 131-141.

Письма в ЖТФ, 2018, том 44, вып. 21 
[9] Alberti A., La Magna A. // J. Appl. Phys. 2013. V. 114. P. 121301 (1-38).

[10] Plusnin N.I. // Mod. Electron. Mater. 2017. V. 3. P. 57-65; Плюснин Н.И. // Изв. вузов. Материалы электронной техники. 2015. Т. 18. № 2. С. 81-94.

[11] Болховитянов Ю.Б., Пчеляков О.П., Чикичев С.И. // УФН. 2001. Т. 171. № 7. C. 689-715.

[12] Кукушкин С.А., Осипов А.В., Шмитт Ф., Хесс П. // ФТП. 2002. Т. 36. В. 10. C. $1177-1185$.

[13] Robertson D., Pound G.M. // J. Cryst. Growth. 1973. V. 19. P. 269-284. 